\title{
Numerical Investigation of Heat Transfer Behaviour During TIG Welding of Stainless Steel Pipes for Various Welding Heat Input Conditions
}

\author{
J. Rajakumar ${ }^{1}$, M. Sheik Ibrahim Bathusa ${ }^{1}$, N. Pothivel Rajan ${ }^{1}$, K. Sulaiman ${ }^{1}$, \\ A. Simon Christopher ${ }^{1}$, K. C. Ganesh ${ }^{2, *}$ \\ ${ }^{1}$ Department of Mechanical Engineering, V V College of Engineering, Tisaiyanvilai, India \\ ${ }^{2}$ Department of Mechanical Engineering, National Institute of Technology, Tiruchirappalli, India \\ Email address: \\ kcgmech@gmail.com (K. C. Ganesh) \\ ${ }^{*}$ Corresponding author
}

\section{To cite this article:}

J. Rajakumar, M. Sheik Ibrahim Bathusa, N. Pothivel Rajan, K. Sulaiman, A. Simon Christopher, K. C. Ganesh. Numerical Investigation of Heat Transfer Behaviour During TIG Welding of Stainless Steel Pipes for Various Welding Heat Input Conditions. American Journal of Mechanical and Industrial Engineering. Vol. 2, No. 3, 2017, pp. 117-126. doi: 10.11648/j.ajmie.20170203.11

Received: October 27, 2016; Accepted: November 7, 2016; Published: February 16, 2017

\begin{abstract}
In the present work, tungsten inert gas (TIG) welding was carried out on stainless steel pipe joints and the heat transfer behaviour for various welding heat input was analysed. In this work austenitic stainless steel of grade 304L was used and the experiment was carried out on bead on plate and weld profile was analysed. The bead profile was obtained from the experiment and microstructure was characterized. The bead profile dimensions from the experiment were used in the calibration of heat source model during finite element heat transfer analysis. Based on the calibrated heat source model, TIG welding of stainless steel pipes was analysed. Numerical simulation was considered as conduction heat transfer analysis and weld pool convection was neglected in the model. The non-linear transient heat transfer analysis was carried out on pipes and thermal cycles at various locations were analysed.
\end{abstract}

Keywords: TIG, 304L, FEA, Transient Temperature, Simulations

\section{Introduction}

Welding is the most widely used, cost-effective means for joining sections of metal to produce an assembly that will perform as if cut or formed from solid material. Proper application of welding technology by the user ensures the making of welds that are "fit for purpose" in virtually all kinds of service. While most people would agree that nuclear power plants, spacecraft, and deep-diving submarines must make use of welding, they might not realize that many vital components, such as high-pressure piping systems, transducers, vacuum tubes, and a multitude of other articles must also use welding in practical production. Without welding, we would be hard-pressed to build computers, television systems, jet planes, and the many devices that support our present mode of living.

The authors [1] attempt to list the recent developments in the area of arc welding heat transfer simulation. Fusion welding modelling is a broad area where a number of research groups were spending their efforts to get solutions for both research and industrial problems. Starting from fundamentals of arc physics, heat transfer, microstructure models, thermal stress, and modern techniques like pattern recognition comes into picture while considering the complete solution of welding-related problems. These areas are developing almost independently and there are only few efforts to couple them together as computational welding mechanics.

Many literature shows the welding related research on the weld bead characteristics. The authors [2] investigated and optimized welding process. The optimization of pulsed gas tungsten arc welding (pulsed GTAW) process parameters was carried out to obtain optimum weld bead geometry with full penetration in welding of stainless steel (304L) sheets of 3 $\mathrm{mm}$ thickness. Weld bead parameters predicted by the models were found to confirm observed values with high accuracy.

The authors [3] investigated the experimental 
investigations of the kinetics of penetration of stainless steel in TIG and ATIG welding, and theoretical analysis of thermal, electromagnetic and hydrodynamic processes occurring in the weld pool metal were conducted. The conjugate model of heat exchange in the base metal and hydrodynamics of the weld pool, with the melt affected by the electromagnetic (Lorentz force), buoyancy (Archimedean force) and thermal-capillary (Marangoni effect) forces, was formulated.

The authors [4] experiments on Laser butt welding of 904L super austenitic stainless steel was conducted using diffusion cooled $3.5 \mathrm{~kW}$ slab $\mathrm{CO}_{2}$ laser welding system. The laser welding process has also been simulated using ANSYS a Finite Element Analysis tool. The effect of laser power, welding speed and focal point position on the bead geometry was investigated. The comparison of the results of the simulation indicates that Finite Element Method (FEM) can predict the responses adequately within the limits of welding parameters being used.

The research [5-7] was focused on the numerical modeling and experimental validation of stainless steel butt joint welding using TIG and ATIG welding process. The models were developed based on conduction heat transfer analysis. It shows that the weld joint behaviour can be analysed with numerical simulation to get an insight on it. This paper [8] describes a study on laser butt welding of 4 and $2 \mathrm{~mm}$ SUS301L stainless steel and a detailed analysis of welding joints was carried out. The gap tolerance of butt joint was also studied with optimized process parameters. It has been

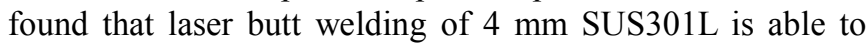
achieve sound metallurgical morphology and high strength weld joint when the butt gap is within certain tolerance.

The authors [9] presented a three-dimensional thermo mechanical finite element (FE) analysis to model and predict the influence of welding sequence on the generation of distortions and residual stresses in large size T-joints. To simulate industrial welding conditions, the influence of nine welding sequences on the magnitude of distortion in both the plate and the stiffener was investigated. The results indicated also that the predicted distortions obtained from threedimensional FE analysis are in reasonable agreement with experimental measurements.

The authors [10] investigated the effects of welding current on the macro-morphology, microstructure and mechanical properties of tungsten inert gas (TIG) welded AZ31 magnesium alloy joints with $\mathrm{TiO}_{2}$ coating were investigated. The results showed that the increase of welding current led to the increase in the depth/width ratio and deteriorated the surface appearance of the welded seams with $\mathrm{TiO}_{2}$ coating.

The authors [11] analysed the use of activating flux in TIG welding process is one of the most notable techniques which are developed recently. In the present study, four oxide fluxes $\left(\mathrm{SiO}_{2}, \mathrm{TiO}_{2}, \mathrm{Cr}_{2} \mathrm{O}_{3}\right.$, and $\left.\mathrm{CaO}\right)$ were used to investigate the effect of activating flux on the depth/width ratio and mechanical property of $316 \mathrm{~L}$ austenitic stainless steel. The effect of coating density of activating flux on the weld pool shape and oxygen content in the weld after the welding process was studied systematically.

The authors [12] investigated the geometrical characteristics of laser weld cross section under different welding conditions. The molten metal behaviours were observed by using the high speed camera and X-ray imaging system to study the formation mechanism of weld cross section. With the increase of welding speed, the width and depth of weld seam decreased, and the geometry of weld cross section changed from bighead shape to needle-like shape.

The authors [13] used Taguchi method to determine the optimal parameters for cladding AISI 304 L stainless steel (SS) with four layers of Inconel $52 \mathrm{M}$ using gas tungsten arc welding (GTAW). The variables included current, voltage, and cladding speed, all of which can affect the cladding angle. Analysis of the microstructure and mechanical properties of the weldments revealed that multiple thermal cycles reduced the hardness of the cladding layer to less than that of the Inconel $52 \mathrm{M}$ cladding layer and AISI $304 \mathrm{~L} \mathrm{SS}$.

The authors [14] investigated the weld profile, impact toughness, microhardness, and microstructure of a JIS SS400 structural multi-layer welding joint using gas-shielded flux cored arc welding (FCAW-G). The microstructure of the welding joints as well as the mechanical properties including impact toughness and microhardness were studied by using a scanning electron microscope (SEM) attached with an energydispersive spectrometer (EDS) and an optical microscopy.

The authors [15] prepared AISI 304 stainless steel welded joint with activated flux tungsten inert gas (A-TIG) method by utilizing self-developed activated flux. It is indicated from the experimental results that for $8 \mathrm{~mm}$-thick AISI 304 stainless steel plate, weld joint of full penetration and oneside welding with good weld appearance can be obtained in a single pass without groove preparation by utilizing A-TIG welding. Moreover, activated flux powders do not cause significant effect on the microstructure of TIG weld and the mechanical properties of A-TIG weld joints are also superior to those of C-TIG (conventional TIG) welding.

The authors [16] studied laser beam welding of dissimilar ferritic / martensitic stainless steels using butt joint configuration with the objective of identifying the influence of the melting ratio between the two base metals on the ultimate shear strength of the welds. Based on a full factorial design, experiments demonstrated that varying the incidence angle up to $45^{\circ}$ and offsetting the focal position with respect to the materials' interface within the limits imposed by the laser spot diameter are a reliable method to control the melting ratio and maintaining the expected resistance length at the material interface.

The authors [17] studied the partial penetration welding with a fiber laser at a $9-\mathrm{kW}$ laser power on 20-mm-thick plates at different positions and analysed by both experimental and numerical methods. The in-depth mechanisms of the energy input characteristics in fiber laser position welding for eight different positions were studied by numerical simulation using the volume-of-fluid (VOF) 
method. Experimental and numerical results were compared for four cases and showed fair agreement.

Based on the literature it was observed that many research work was carried out on various welding processes and the weld joint integrity was investigated. Also, noticed that most of the welding experiments were under laboratory scale and real time structures were not investigated. In this research, the heat transfer behaviour during the TIG welding of pipes were analysed using numerical modeling. The analysis was carried out for various welding heat input conditions that gave an insight on the welding behaviour on real structures used in industrial applications.

\section{Materials and Methods}

In this investigation TIG welding with various heat input was studied on the heat transfer behaviour of pipes as shown in Figure 1. The pipe of $5 \mathrm{~mm}$ thickness and shorter length was chosen compare to practical application as the objective of the investigation was limited to heat transfer behaviour. The simulation of pipes was investigated with square butt joint configuration using single pass autogenous TIG welding. The welding was carried out in various heat input conditions and the induced transient heat transfer was analysed. The pipe material was considered as 304L austenitic stainless steel that does not undergo solid state phase transformation during melting and solidification.

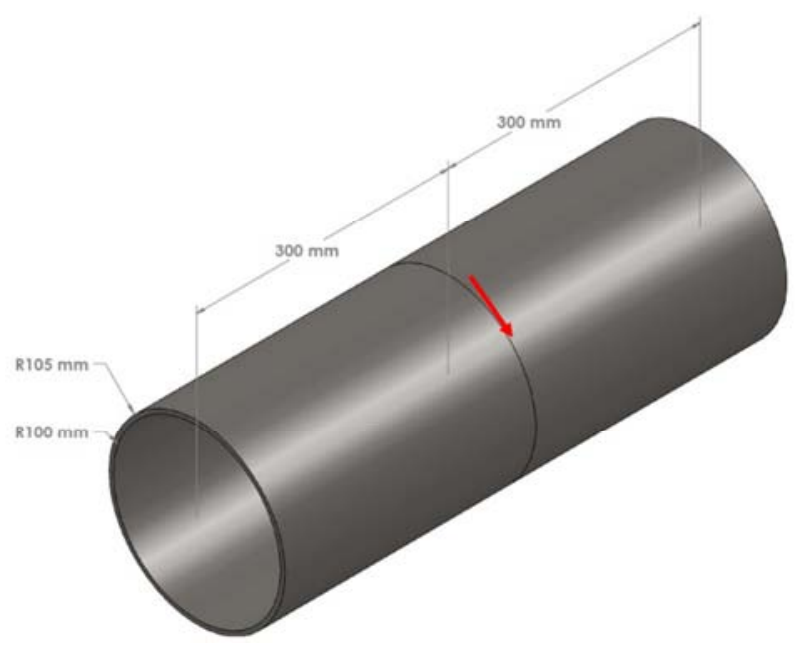

Figure 1. Pipe Joint Configuration.

\section{Finite Element Analysis}

\subsection{Mesh Generation}

The pipes were meshed with hexahedron linear elements that can calculate the field variables precisely. Various zone of pipe was meshed with different element sizes as shown in Figure 2. During welding, a localized zone was melted and the thermal gradient around the melting zone was higher. To capture the induced temperature precisely, the welding zone was meshed finer that the base metal region. Overall the component consists of 28,000 hexahedron elements to calculate the thermal effects.

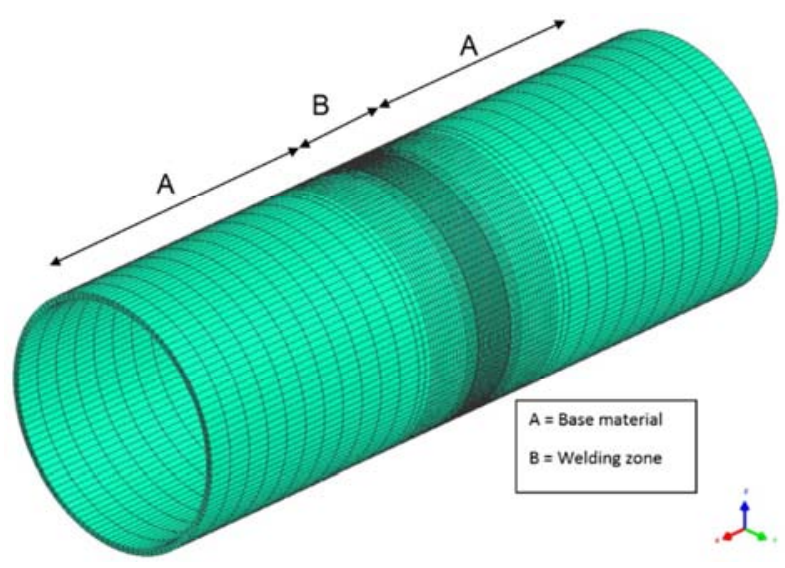

Figure 2. Meshed component.

\subsection{Governing Equations}

In the welding simulation, the transient heat transfer analysis was governed by the following equation,

$$
\rho c \frac{\partial T}{\partial t}(x, y, z, t)=-\nabla \cdot \vec{q}(x, y, z, t)+Q(x, y, z, t)
$$

where $\rho$ is the density of the materials, $\mathrm{c}$ is the specific heat capacity, $\mathrm{T}$ is the current temperature, $\mathrm{q}$ is the heat flux vector, $\mathrm{Q}$ is the internal heat generation rate, $\mathrm{x}, \mathrm{y}$ and $\mathrm{z}$ are the coordinates in the reference system, $t$ is the time.

\subsection{Material Property}

The pipe was considered as 304L austenitic stainless steel which has only austenite phase. The weld zone may have a small quantity of $\delta$-ferrite, but still it would not contribute in the formation of detrimental residual stress. By considering this phenomenon, the material was assumed as single phase and used in the model.

The weld pool dynamics of the process was neglected and the weld pool was considered as solid phase that would neglect the need of mass and momentum equations to be solved. Also the model was neglected the latent heat of fusion and the material properties were used as temperature dependent which induced the material non-linearity in the problem. The material property used in this analysis is given as follows,

Table 1. Material properties.

\begin{tabular}{llll}
\hline $\begin{array}{l}\text { Temperature } \\
\left({ }^{\circ} \mathbf{C}\right)\end{array}$ & $\begin{array}{l}\text { Specific heat } \\
\left(\mathbf{J} / \mathbf{g}^{\circ} \mathbf{C}\right)\end{array}$ & $\begin{array}{l}\text { Conductivity } \\
\left(\mathbf{J} / \mathbf{m m}{ }^{\circ} \mathbf{C}\right)\end{array}$ & $\begin{array}{l}\text { Density } \\
\left(\mathbf{g} / \mathbf{m m}^{\mathbf{3}}\right)\end{array}$ \\
\hline 100 & 0.496 & 0.0151 & 0.788 \\
200 & 0.512 & 0.0161 & 0.783 \\
300 & 0.525 & 0.0179 & 0.779 \\
400 & 0.540 & 0.0180 & 0.775 \\
600 & 0.577 & 0.0208 & 0.766 \\
800 & 0.604 & 0.0239 & 0.756 \\
1200 & 0.676 & 0.0322 & 0.737 \\
1300 & 0.692 & 0.0337 & 0.732 \\
\hline
\end{tabular}




\subsection{Boundary Conditions}

The model was assumed as symmetric in nature and one pipe was modeled in the analysis. The meshed pipe model given in the Figure 2, was mirrored to get an understanding of the pipe welding. Except the symmetric surface, other surfaces were applied to combined convection and radiation heat loss since it has interaction with the atmosphere. The initial condition of the model was considered with $30^{\circ} \mathrm{C}$ which was the atmospheric temperature before welding start.

\subsection{Heat Input Condition}

The molten weld pool in this analysis was represented using double ellipsoidal heat source model. The required dimensions of the heat source parameters were measured from a preliminary welding experiment and substituted in the simulation. The following equation shows the double ellipsoidal welding heat source that calculates the volumetric heat flux applied to the pipe model.

$$
\begin{aligned}
& Q(x, y, z, t)=\left(\frac{6 \sqrt{3} f_{f} Q}{a_{1} b c \sqrt{\pi}}\right) * e^{-3 x^{2} / a_{1}^{2}} * e^{-3 y^{2} / b^{2}} * e^{-3 z^{2} / c^{2}} \\
& Q(x, y, z, t)=\left(\frac{6 \sqrt{3} f_{r} Q}{a_{2} b c \sqrt{\pi}}\right) * e^{-3 x^{2} / a_{2}^{2}} * e^{-3 y^{2} / b^{2}} * e^{-3 z^{2} / c^{2}}
\end{aligned}
$$

The heat input to this equation was calculated and given in the following table. The arc efficiency was assumed as $70 \%$. The analysis was carried out for various heat input conditions as given in Table 2 .

Table 2. Welding input parameters.

\begin{tabular}{lllll}
\hline S. No & Current (A) & Voltage (V) & $\begin{array}{l}\text { Speed } \\
(\mathbf{m m} / \mathbf{s})\end{array}$ & $\begin{array}{l}\text { Heat input } \\
(\mathbf{J} / \mathbf{m m})\end{array}$ \\
\hline 1 & 100 & 10 & 1.666667 & 420 \\
2 & 125 & 10 & 1.666667 & 525 \\
3 & 150 & 10 & 1.666667 & 630 \\
4 & 175 & 10 & 1.666667 & 735 \\
5 & 200 & 10 & 1.666667 & 840 \\
\hline
\end{tabular}

\section{Results and Discussion}

\subsection{Weld Bead Profile}

The bead-on-plate welding was carried out on the 304L stainless steel and the bead profile is given in Figure 3. The welding was carried out using $80 \mathrm{~A}$ current and $100 \mathrm{~mm} / \mathrm{min}$ speed. It was induced partial penetration on the $5 \mathrm{~mm}$ stainless steel.

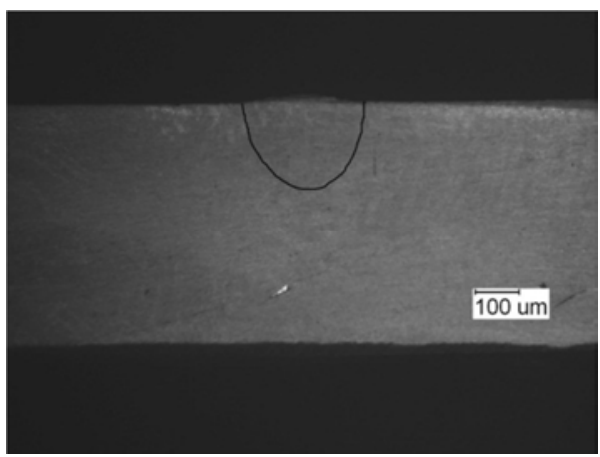

Figure 3. Weld Bead.

The microstructure of the weld bead profile is given in Figure 4. It is clear that the weld bead profile has austenite and $\delta$-ferrite in the welded zone. The presence of ferrite reduces the hot cracking susceptibility during welding solidification.

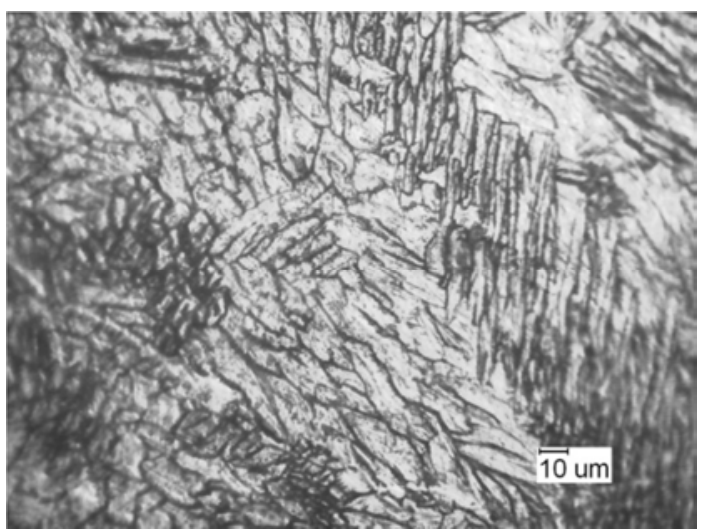

Figure 4. Microstructure.

\subsection{Temperature Contours}

The temperature, contour of model with various welding heat inputs is presented in the following figures. The trial number represented the heat input as given in the previous table. The figures show the transient heat transfer results that were induced by the moving heat source. The heat source was moving as welding happens through the circumference of pipe joint and cools down to room temperature.

The results show the temperature distribution during welding followed by cooling of a welded joint. In all the welding simulations the temperature attained quasi steady state and there was no fluctuation in the peak temperature. The peak temperature for various welding heat was reached as $1610,1899,2167,2413$ and $2638^{\circ} \mathrm{C}$ respectively. The temperature at various time shows that the welding was happening circumferentially and the trailing contours shows the temperature distribution at the weld joint. 

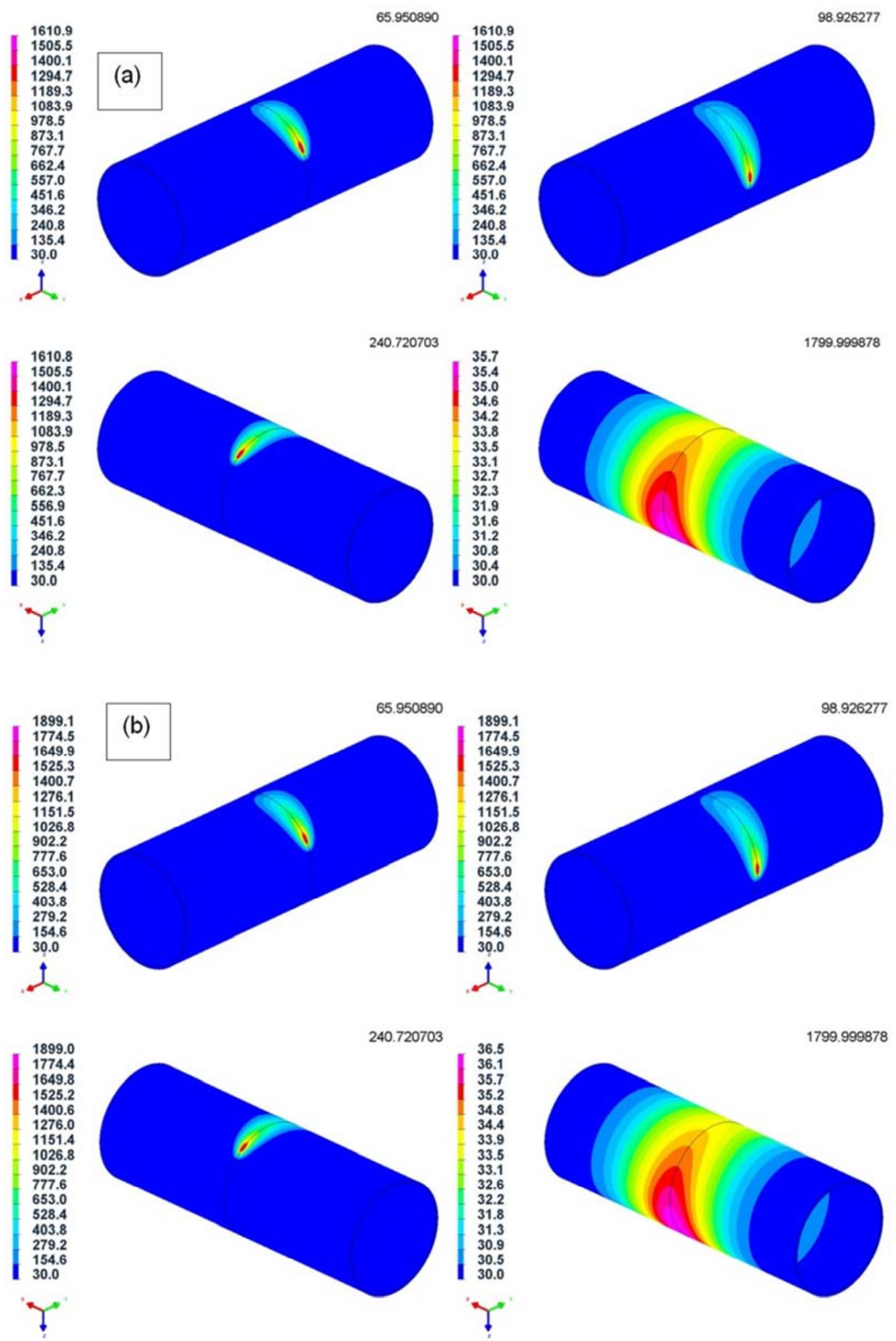

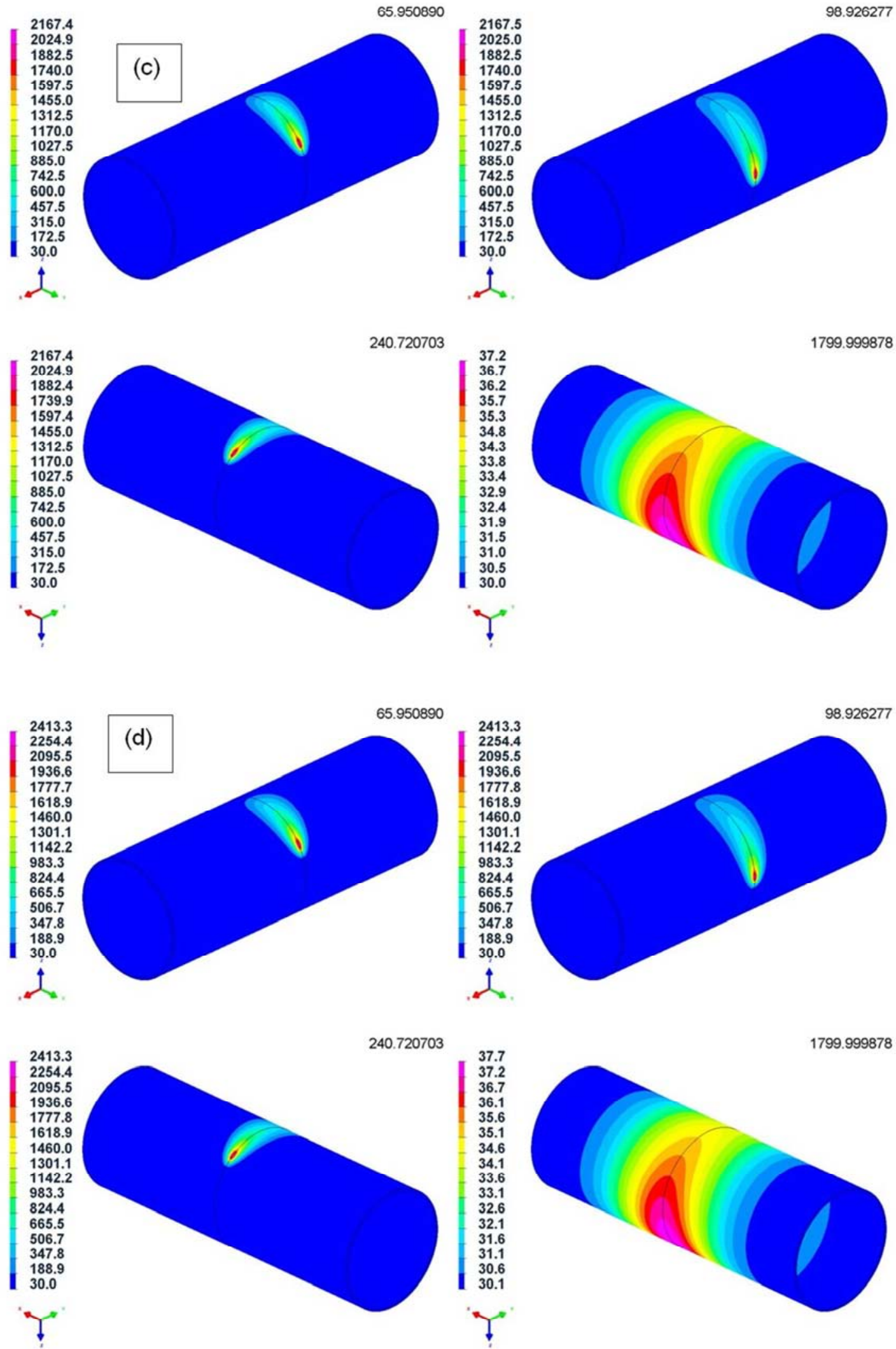

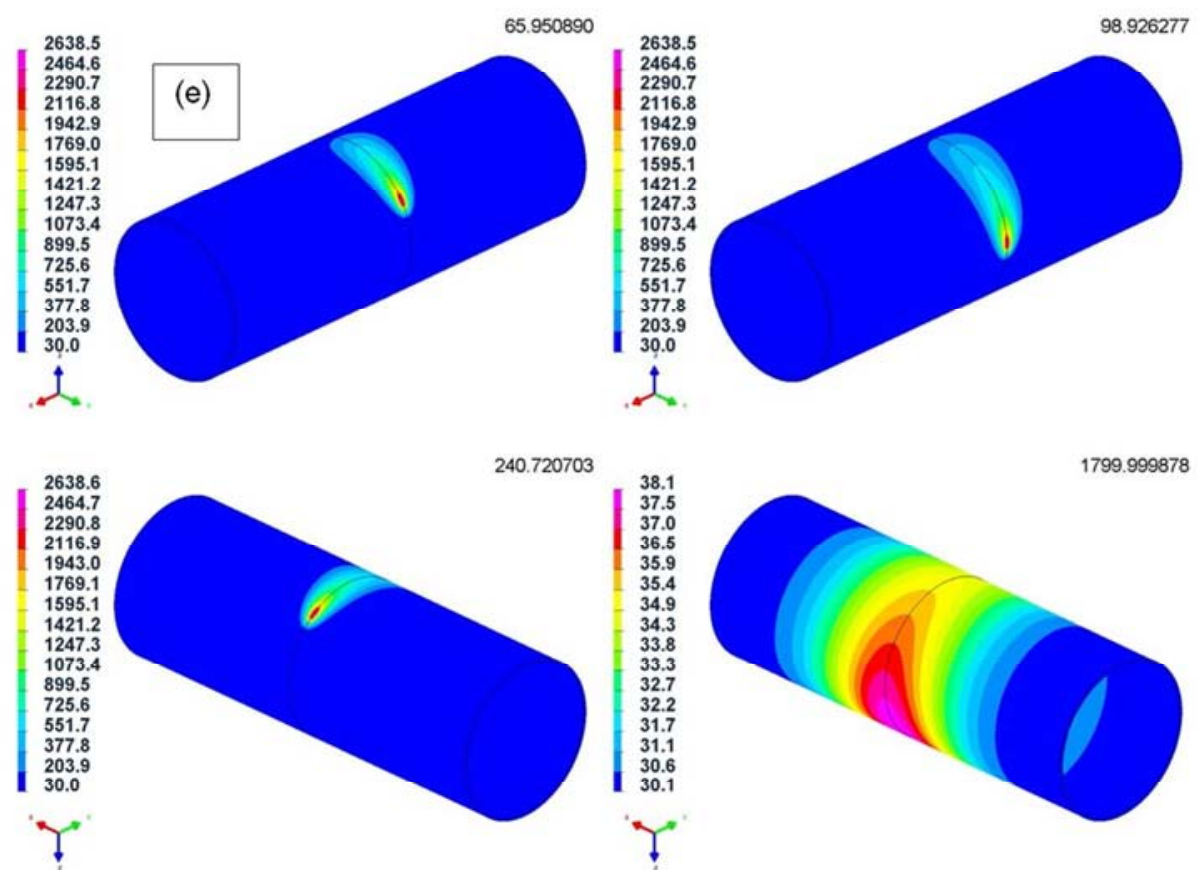

Figure 5. Temperature Contours, (a). 100A, (b). 125A, (c). 150A, (d). 175A, (e). 200A

The following plot shows the peak temperature for various heat inputs. The linear curve fit to the data shows the correlation between the welding heat input and the induced peak temperature. The peak temperature varies $2.448^{\circ} \mathrm{C}$ for unit change in the welding heat input of this analysis. As the heat input increases the peak temperature linearly increases in the graph, but the peak temperature may not be realistic for higher heat input as the weld pool convection was neglected which could reduce the peak temperature.

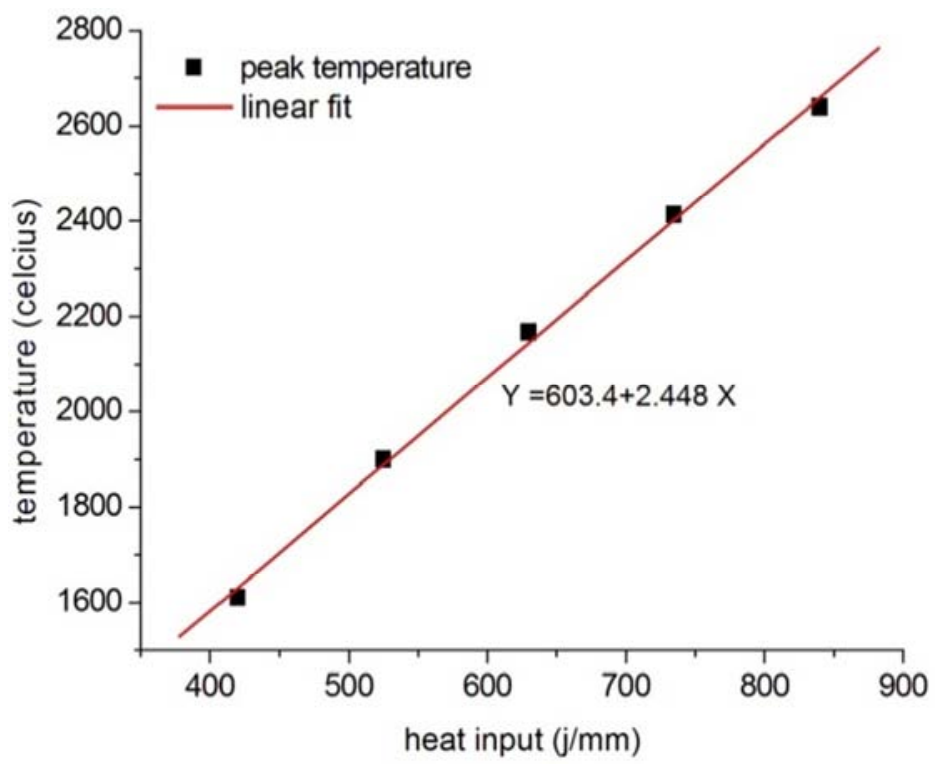

Figure 6. Peak Temperature.

\subsection{Thermal Cycles at Start / End}

The following figures show the thermal cycles at the start and end of welding. As the welding start using high frequency start that has a higher input supply to establish the welding arc, the heat source was fitted to have a higher initial energy supply that induced higher peak temperature at the beginning. Since the orbital welding completed at the same location, the thermal cycle shows two various peak temperature cycles. This thermal cycle for all the simulations were taken at the start / end point which shows a similar trend and various amplitudes of temperature due to the variation in heat input. 

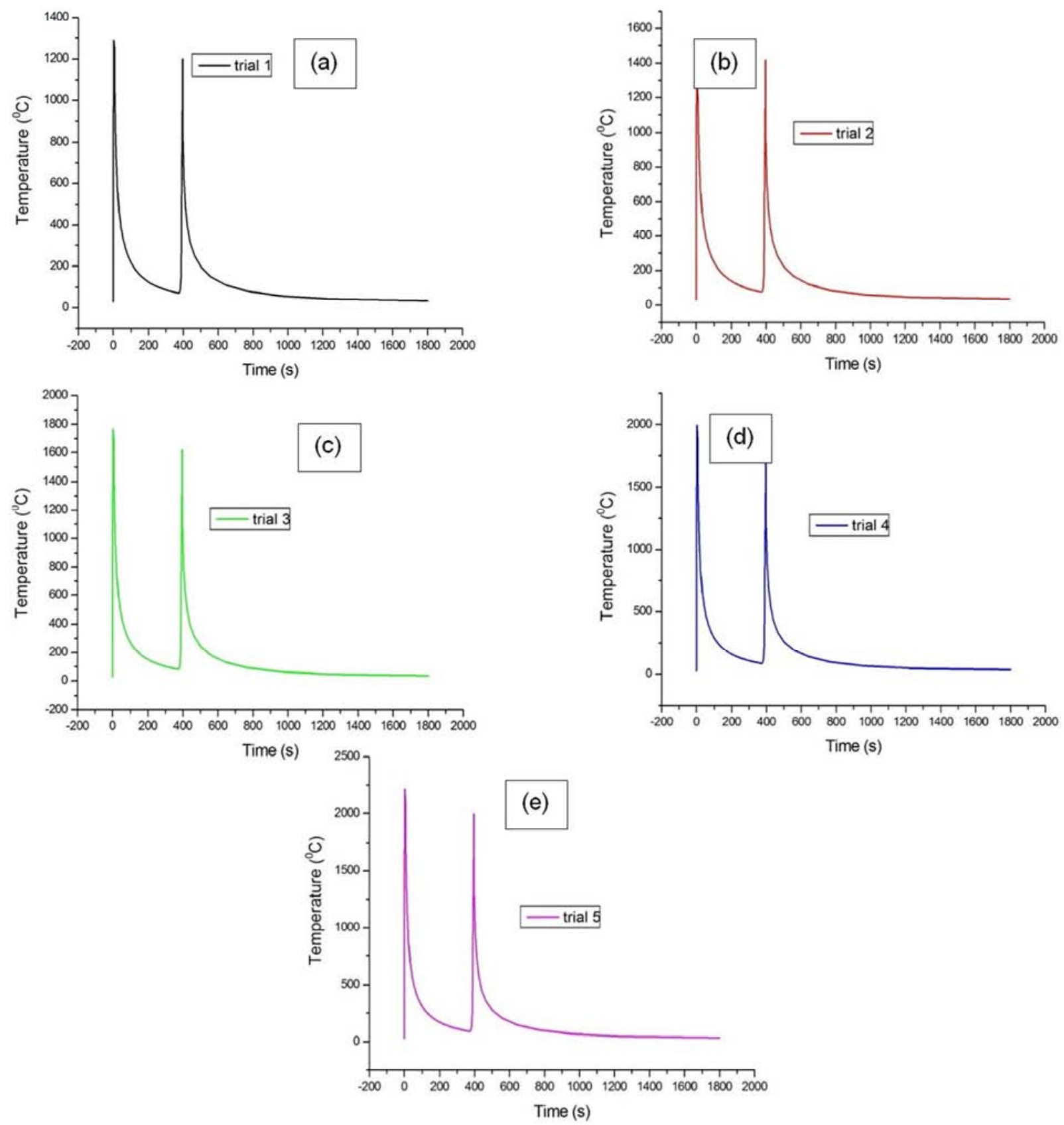

Figure 7. Thermal cycles at start and end of welding, (a). 100A, (b). 125A, (c). 150A, (d). 175A, (e). 200A

\subsection{Transverse Thermal Cycles}

The following figures show the transverse thermal cycles at $270^{\circ}$ from the welding start point. The thermal cycle curves are given a maximum of $600 \mathrm{~s}$ of the total simulation. The beginning of plots shows constant initial temperature as the heat source was away from the measurement point. 

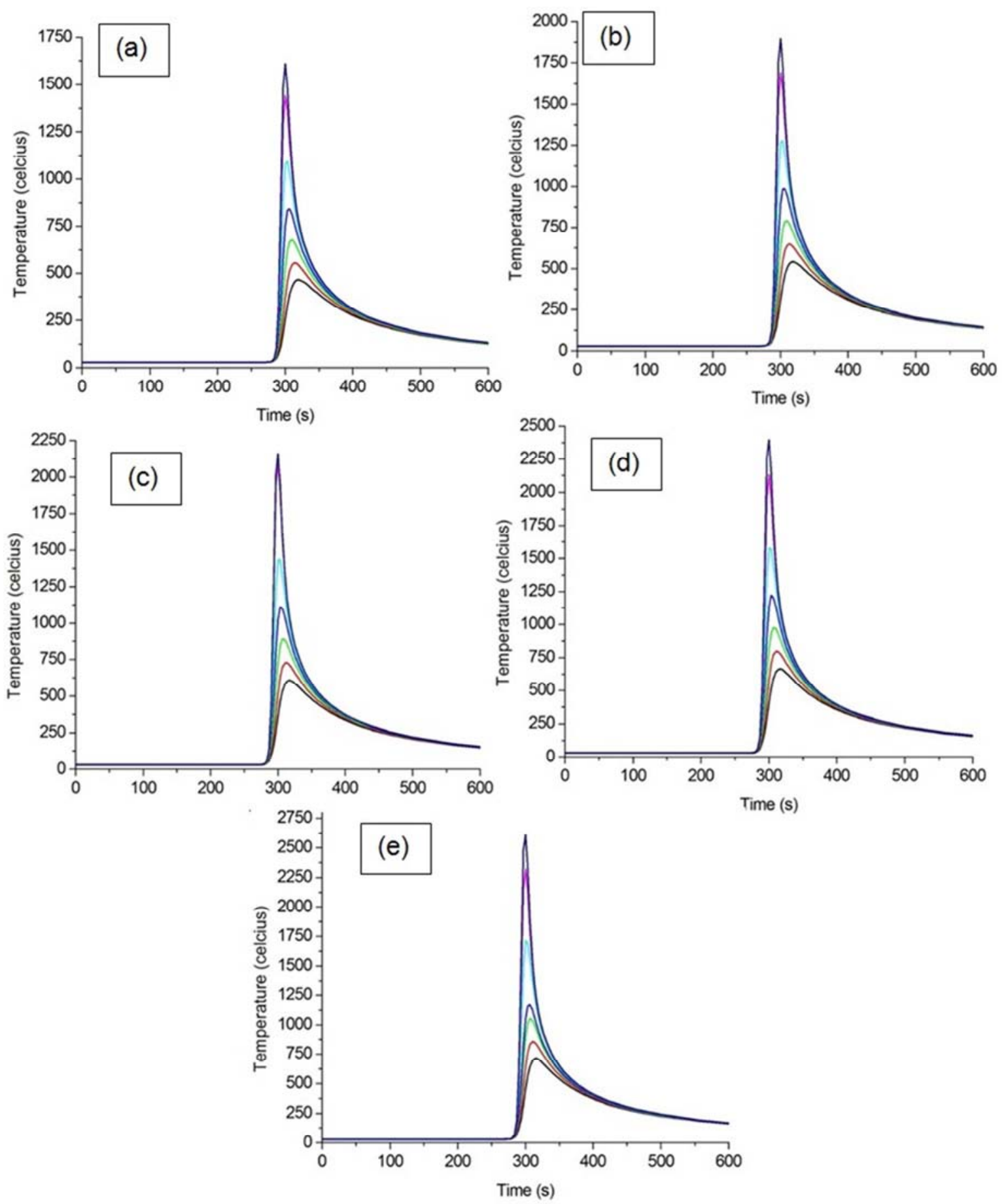

Figure 8. Transverse Thermal Cycle, (a). 100A, (b). 125A, (c). 150A, (d). 175A, (e). $200 \mathrm{~A}$.

The peak temperature keeps on reducing in the transverse direction as the temperature gradient is higher near to the welding heat source. Also the lower thermal conductivity of the stainless steel conducts the temperature slowly. But the amplitude of transient temperature distribution is increasing as the heat input is increased.

\section{Conclusions}

This research was carried out to understand the heat transfer behaviour during TIG welding of pipes as it is widely being used in many industries. The numerical models were developed that give an insight on the temperature profiles of the welded pipes. The outcome of this research is summarized as follows,

- A bead on plate experiment was carried out to understand the weld bead profile and microstructure. The experimentally obtained weld bead profile shows the partial penetration of bead and the weldment has austenite and ferrite microstructure.

- Finite element model was developed and heat source was calibrated based on experimentally observed weld 
bead profile using SYSWELD software.

- The welding was investigated for various heat input and the transient temperature induced on the welded joint was analysed.

- The contour plots of various heat input welding were presented that shows the increased peak temperature as the welding heat input was increased. As the heat input was increased, it dispersed more temperature around the welding heat source that increased the temperature intensity adjacent to the welding heat source.

- The peak temperature of the welding analysis was varied between $1600^{\circ} \mathrm{C}$ and $2600^{\circ} \mathrm{C}$. It is observed that the peak temperature at higher heat input was very high as the convection effects of weld pool was neglected during the simulation.

- The temperature was keep on decreasing in the transverse direction of welded joint. It was noticed that the thermal cycle at the start and end of the welding point shows different thermal cycle profile.

\section{References}

[1] Varghese VMJ, Suresh MR, Kumar DS (2012) Recent developments in modeling of heat transfer during TIG welding - a review. The International Journal of Advanced Manufacturing Technology 64 (5-8):749-754. doi:10.1007/s00170-012-4048-9

[2] Giridharan PK, Murugan N (2009) Optimization of pulsed GTA welding process parameters for the welding of AISI 304L stainless steel sheets. The International Journal of Advanced Manufacturing Technology 40 (5-6):478-489. doi:10.1007/s00170-008-1373-0

[3] Yushchenko KA, Kovalenko MDV, Krivtsun IV, Demchenko VF, Kovalenko MIV, Lesnoy MAB (2009) Experimental Studies and Mathematical Modelling of Penetration in TIG and A-TIG Stationary Arc Welding of Stainless Steel. Welding in the World 53 (9-10):R253-R263

[4] Abhilash AP, Sathiya P (2011) Finite Element Simulation of Laser Welding of 904L Super Austenitic Stainless Steel. Transactions of the Indian Institute of Metals 64 (4-5):409416. doi:10.1007/s12666-011-0093-6

[5] Ganesh KC, Balasubramanian KR, Vasudevan M, Vasantharaja P, Chandrasekhar N (2016) Effect of Multipass TIG and Activated TIG Welding Process on the ThermoMechanical behaviour of 316LN Stainless Steel Weld Joints. Metallurgical and Materials Transactions B 47 (2):1347-1362. doi:10.1007/s11663-016-0600-6

[6] Ganesh KC, Vasudevan M, Balasubramanian KR, Chandrasekhar N, Vasantharaja P (2014) Thermo-mechanical Analysis of TIG Welding of AISI 316LN Stainless Steel. Materials and Manufacturing Processes 29 (8):903-909. doi:10.1080/10426914.2013.872266

[7] Ganesh KC, Vasudevan M, Balasubramanian KR,
Chandrasekhar N, Mahadevan S, Vasantharaja P, Jayakumar T (2014) Modeling, Prediction and Validation of Thermal Cycles, Residual Stresses and Distortion in Type 316 LN Stainless Steel Weld Joint made by TIG Welding Process. Procedia Engineering 86:767-774. doi:10.1016/j.proeng.2014.11.096

[8] Lu SP, Qin MP, Dong WC (2013) Highly efficient TIG welding of Cr13Ni5Mo martensitic stainless steel. J Mater Process Technol 213 (2):229-237. doi:10.1016/j.jmatprotec.2012.09.025

[9] Keivani R, Jahazi M, Pham T, Khodabandeh AR, Afshar MR (2014) Predicting residual stresses and distortion during multisequence welding of large size structures using FEM. The International Journal of Advanced Manufacturing Technology 73 (1-4):409-419. doi:10.1007/s00170-014-58334

[10] Shen J, Zhai D-j, Liu K, Cao Z-m (2014) Effects of welding current on properties of A-TIG welded AZ31 magnesium alloy joints with $\mathrm{TiO} 2$ coating. Transactions of Nonferrous Metals Society of China 24 (8):2507-2515. doi:10.1016/S10036326(14)63377-X

[11] Ahmadi E, Ebrahimi AR (2015) Welding of 316L Austenitic Stainless Steel with Activated Tungsten Inert Gas Process. Journal of Materials Engineering and Performance 24 (2):1065-1071. doi:10.1007/s11665-014-1336-6

[12] Li S, Chen G, Zhou C (2015) Effects of welding parameters on weld geometry during high-power laser welding of thick plate. The International Journal of Advanced Manufacturing Technology 79 (1-4):177-182. doi:10.1007/s00170-015-6813$\mathrm{z}$

[13] Lin C-M, Su T-L, Wu K-Y (2015) Effects of parameter optimization on microstructure and properties of GTAW clad welding on AISI 304L stainless steel using Inconel 52M. The International Journal of Advanced Manufacturing Technology 79 (9-12):2057-2066. doi:10.1007/s00170-015-6875-y

[14] Ling K-H, Fuh Y-K, Kuo T-C, Xun-Tu S (2015) Effect of welding sequence of a multi-pass temper bead in gas-shielded flux-cored arc welding process: hardness, microstructure, and impact toughness analysis. The International Journal of Advanced Manufacturing Technology 81 (5-8):1033-1046. doi:10.1007/s00170-015-7277-x

[15] Liu G-h, Liu M-h, Yi Y-y, Zhang Y-p, Luo Z-y, Xu L (2015) Activated flux tungsten inert gas welding of $8 \mathrm{~mm}$-thick AISI 304 austenitic stainless steel. Journal of Central South University 22 (3):800-805. doi:10.1007/s11771-015-2585-8

[16] Romoli L, Rashed CAA (2015) The influence of laser welding configuration on the properties of dissimilar stainless steel welds. The International Journal of Advanced Manufacturing Technology 81 (1-4):563-576. doi:10.1007/s00170-015-72348

[17] Sohail M, Han S-W, Na S-J, Gumenyuk A, Rethmeier M (2015) Numerical investigation of energy input characteristics for high-power fiber laser welding at different positions. The International Journal of Advanced Manufacturing Technology 80 (5-8):931-946. doi:10.1007/s00170-015-7066-6 